\section{Comparison of Resin-coated and Soluble Fertilizer Formulations in the Production of Zonal Geranium, Potted Chrysanthemum, and Poinsettia}

\author{
Harry K. Tayama ${ }^{1}$ and \\ Stephen A. Carver ${ }^{2}$
}

Additional index words. Pelargonium hortorum, Dendranthema grandiflora Euphorbia pulcherrima, resin-coated, nutrient uptake, growth, flowering

Summary. A series of crop-specific, resin-coated, controlled-release fertilizer formulations, including: Sierra Geranium Mix 13-12-11 Plus Minors, Sierra Chrysanthemum Mix 1210-17 Plus Minors, and Sierra Poinsettia Mix 12-12-15 Plus Minors were preplant-incorporated into Metro Mix 350 growing medium for the production of potted zonal geraniums, chrysanthemum, and poinsettia. Plant growth and foliar nutritional responses were compared to those obtained from plants produced with a standard resin-coated, controlled-release Osmocote formulation (19N$6 \mathrm{P}-12 \mathrm{~K})$, water-soluble Peters 20N10P-20K, and a combination of water-soluble and resin-coated treatments. Crops produced with specialty resin-coated mixes (at recommended rate $=1 \times$ ) were equal in growth and flowering characteristics to those produced with Osmocote $(1 \times)$, water-soluble (200 ppm nitrogen), or a combination of water-soluble (200 ppm nitrogen) and resin-coated $(0.5 \times)$ fertilizer treatments. Foliar analyses revealed elemental concentrations in resin-coated fertilizer-treated plants were below those in water-soluble or combination treatments, but were within a range to support satisfactory quality crop production.

Department of Horticulture, The Obio State University 2001 Fyffe Count, Columbus, OH 43210.

'Professor.

${ }^{2}$ Research Associate
$\mathrm{F}$ ertilization is a basic component of greenhouse crop management. The principal means of fertilization include 1) application of controlled-release fertilizers incorporated into or top-dressed onto the growing medium, 2) injection of water-soluble fertilizers into the irrigation stream, or 3) a combination of the two. Each technique has its merits. Benefits of controlled-release fertilizers include 1) application of the total fertilizer charge made at or prior to planting, and 2) gradual nutrient release, which allows for efficient fertilizer uptake and usage.

Two controlled-release fertilizers that have become standards in the greenhouse industry (Osmocote 1414-14 and Osmocote 19-6-12) are composed of water-soluble fertilizer prills covered with a resin film. Fertilizer release into the growing medium is mediated by moisture, with release rate governed by composition and thickness of the resin film and by growing medium temperature. Both Osmocote formulations are designed to release their contents over 3 -months at a growing medium temperature of $70 \mathrm{~F}$ (21C). This is suitable for production of most floriculture greenhouse crops. Osmocote formulations, either alone or in combination with injection of water-soluble fertilizers, have been used to produce satisfactory quality Lilium longiflorum (Kiplinger et al., 1972); Celosia cristata, Dendranthema gandiflora, and Euphorbia pulcherrima (Maynard and Lorenz, 1979); Kalanchoe blossfeldiana Pixie (Kovacic and Holcomb, 1981); and Saintpaulia ionantha Ulli and Lisa (Payne and Adams, 1980).

Three crop-specific, controlledrelease, resin-coated fertilizer formulations have been released for zonal geraniums, chrysanthemums, and poinsettias. These specialized mixes are designed to deliver proper ratios of essential nutrients required for optimum production. In a preliminary study, poinsettias fertilized with a then-still experimental Sierra Poinsettia Mix 12-12-15 Plus Minors at the recommended rate or $1.5 \times$ exhibited significantly reduced vegetative growth, floral response, and leaf elemental concentration compared to those fertilized with Osmocote 19-612 or Peters 20-10-20 (Tayama and Carver, 1988). The study was repeated using commercially available Sierra 
Poinsettia Mix 12-12-15 Plus Minors, along with Sierra Geranium Mix 13-12-11 Plus Minors, and Sierra Chrysanthemum Mix 12-10-17 Plus Minors.

This study included two geranium, one poinsettia, and two chrysanthemum trials. Each trial included seven treatments arranged in a randomized-block design with three replicates per treatment and six (geranium) or three (poinsettia and chry santhemum) pots per replication. The seven treatments were 1) no fertilizer control, 2) Peters 20-10-20 Peat-Lite Special at 200 ppm N at every irrigation, 3) Sierra specialty Mix Plus Minors at $1 \times, 4)$ Sierra specialty Mix at $1.5 \times$, 5) Sierra specialty Mix at 0.5× plus Peters 20-10-20 Peat-Lite Special at every irrigation at $200 \mathrm{ppm}$ nitrogen, 6) Osmocote 19-6-12 at $1 \times$, and 7) Osmocote 19-6-12 at $0.5 \times$ plus Peters. The specialty and Osmocote resin-coated fertilizer formulations were preplant-incorporated into the medium. The recommended $(1 \times)$ rates for the formulations used were 9 $\mathrm{lb} / \operatorname{yard}^{3}\left(5.3 \mathrm{~kg} \mathrm{~m}^{-3}\right)$ of Poinsettia Mix, Chrysanthemum Mix, or Osmocote, and $12 \mathrm{lb} /$ yard $^{3}\left(7.1 \mathrm{~kg} \mathrm{~m}^{-3}\right)$ of $\mathrm{Ge}$ ranium Mix. The medium was irrigated as required with a solution containing $200 \mathrm{ppm}\left(200 \mathrm{mg} \mathrm{liter}^{-1}\right) \mathrm{N}$ from Peters 20-10-20 or with tap water only, as dictated by the treatment. At the end of each experiment, leaf samples (youngest fully expanded leaves) were collected and submitted to the Research and Extension Analytical Laboratory, Ohio Agricultural Research and Development Center, The Ohio State Univ., for analysis. Chemical growth regulators were applied as a spray, 1 gal of solution per $200 \mathrm{ft}^{2}\left(204 \mathrm{ml} \mathrm{m}^{-2}\right)$ of bench space.

Zonal generation. The two zonal geranium trials were conducted concurrently, beginning 15 Jan. 1989, when 2.5- to 3-inch $(7-\mathrm{cm})$ calloused Your s Truly cuttings were stuck in Oasis Strips and placed under intermittent mist with 70F (21C) minimum night temperature. Three weeks later, rooted cuttings were removed from the mist, planted one per 4.5-inch (11-cm) pot in Metro-Mix 350 growing medium amended with resincoated fertilizer as required by the treatment, and placed on 6-inch $(15-\mathrm{cm})$ staggered centers in an unshaded glasshouse, with 60F (15.5C) minimum night temperature. Gerani- urns were not pinched, but were sprayed with Cycocel (chlormequat) at $1500 \mathrm{ppm}$ a.i. (1.5 g a.i./liter) on 26. Foliar samples (30 most recently expanded leaves among six subsamples within each replication) for nutrient analyses and plant growth data were collected on 30 Mar. Days to flower were determined from the day plants were removed from the mist house until the first flower on the first inflorescence within each treatment/replication opened. Data from the two trials were combined for analyses and presentation.

There were few differences in plant growth among water-soluble, fertilizer combination, or $1.0 \times$ Geranium Mix fertilizer treatments (Table 1). Plants fertilized with the $1.0 \times$ rate of Osmocote were significantly smaller than for any other treatment except control. There were no differences among fertilizer treatments in the number of flowers produced or days to flower. Elemental concentrations in plants receiving water-soluble or combination fertilizer treatments were generally in or above the range of sufficiency for $\mathrm{N}, \mathrm{P}, \mathrm{K}$, and $\mathrm{Mg}$, but concentrations of $\mathrm{Ca}$ were insufficient. Plants grown with Osmocote at 1.0x rate had leaf $\mathrm{N}$ concentrations slightly below sufficiency, but higher Ca levels than any other treatment. All micronutrients were within the sufficient concentration range for all treatment groups.

Potted chysanthemum. The first chrysanthemum trial was initiated 14 July 1989, when Bright Golden Anne rooted cuttings were planted five per 6.5 -inch $(16.5-\mathrm{cm})$ pot in amended Metro-Mix 350, amended as required for treatment. The plants were placed under intermittent mist for a week after planting, and then moved to a whitewashed glass greenhouse with 67F (19.5C) minimum night temperature and spaced on 9-inch $(23-\mathrm{cm})$ centers for 4 weeks, followed by a final staggered spacing of 15 -inch $(38-\mathrm{cm})$ centers. Plants were pinched to seven leaves when roots had reached the bottom of the pots on 4 Aug., at which time short-day treatment began. BNine (daminozide) at $5000 \mathrm{ppm}$ a.i. (5.0 g a.i/liter) was applied when 1.5 inches $(3.8 \mathrm{~cm})$ of new growth was evident (11 Aug.), and again 2 and 4 weeks later. The plants were disbudded 8 Sept. Foliar samples (24 most recently expanded leaves among three subsamples within each replication) for nutrient analysis and plant growth data were collected on 6 Oct. Days to flower were determined from the day plants were removed from the mist house until half the flowers in each pot were about one-half open (eight to 10 rows of ray florets open). The second chrysanthemum trial, using the same protocol, was initiated 30 Nov. 1989. Data from the two trials were combined for analyses and presentation.

There were no significant differences in plant height or days to flower among plants in all treatment groups (Table 2). Plants produced with resincoated fertilizers plus soluble fertilizers were widest; plants fertilized with Chrysanthemum Mix at $1 \times$ and $1.5 \times$ rates produced the greatest number of flowers. Leafelemental concentrations among the treatments were very similar to those observedwith zonal geraniums except that $\mathrm{Ca}$ concentrations were all within the sufficiency range. Nitrogen, $\mathrm{P}$, and $\mathrm{K}$ concentrations were generally highest in all treatments receiving

Table 1. Zonal geranium Tours Truly growth and foliar elemental concentrations with different fertilizer regimes.

\begin{tabular}{|c|c|c|c|c|c|c|c|}
\hline \multirow[b]{2}{*}{ Treatment } & \multicolumn{2}{|c|}{ Plant growth $(\mathrm{cm})$} & \multicolumn{5}{|c|}{ Element $(\%)$} \\
\hline & Height & Diameter & $\mathbf{N}$ & $\mathbf{P}$ & $\mathbf{K}$ & $\mathrm{Ca}$ & $\mathrm{Mg}$ \\
\hline Control & 9 & 16 & 1.6 & 0.3 & 2.9 & 0.9 & 0.3 \\
\hline Peters alone $(200 \mathrm{ppm} \mathrm{N})$ & 14 & 24 & 5.4 & 0.8 & 4.4 & 1.0 & 0.3 \\
\hline \multicolumn{8}{|c|}{ Geranium mix at $0.5 x$} \\
\hline plus Peters & 14 & 25 & 5.8 & 0.5 & 4.4 & 1.0 & 0.4 \\
\hline Geranium mix at $1 x$ & 14 & 25 & 4.1 & 0.6 & 3.8 & 1.2 & 0.5 \\
\hline Geranium mix at $1.5 x$ & 14 & 25 & 4.7 & 0.8 & 4.1 & 1.1 & 0.5 \\
\hline \multicolumn{8}{|l|}{ Osmocote at $0.5 x$} \\
\hline plus Peters & 15 & 26 & 5.5 & 0.9 & 4.2 & 1.0 & 0.3 \\
\hline Osmocote at $1 x$ & 12 & 22 & 3.3 & 0.3 & 3.5 & 1.3 & 0.4 \\
\hline Sufficient ${ }^{7}$ & & & $3.8-4.4$ & $0.3-0.5$ & $2.6-3.5$ & $1.4-2.00$ & $.2-0.4$ \\
\hline $\mathrm{LSD}_{0.05}$ & 1.0 & 1.4 & 0.36 & 0.18 & 0.27 & 0.10 & 0.02 \\
\hline
\end{tabular}


Table 2. Chrysanthemum Bright Golden Anne plant diameter, flower number, and foliar elemental concentrations with different fertilizer regimes.

\begin{tabular}{|c|c|c|c|c|c|c|c|}
\hline \multirow[b]{2}{*}{ Treatment } & \multicolumn{2}{|c|}{ lant diam } & \multicolumn{5}{|c|}{ Element $(\%)$} \\
\hline & $(\mathrm{cm})$ & No. flowers & $\mathbf{N}$ & $\mathbf{P}$ & $\mathrm{K}$ & $\mathrm{Ca}$ & $\mathrm{Mg}_{\mathrm{g}}$ \\
\hline Control & 27 & 8 & 2.5 & 0.6 & 4.6 & 1.4 & 0.4 \\
\hline Peters alone $(200 \mathrm{ppm} \mathrm{N})$ & 50 & I 1 & 5.6 & 0.9 & 6.9 & 1.9 & 0.7 \\
\hline \multicolumn{8}{|l|}{ Chrysanthemum mix at } \\
\hline $0.5 \times$ plus Peters & 53 & 10 & 5.5 & 1.0 & 7.0 & 1.8 & 0.7 \\
\hline Chrysanthemum mix at $I x$ & 51 & 14 & 5.0 & 0.7 & 6.1 & 1.8 & 0.7 \\
\hline $\begin{array}{l}\text { Chrysanthemum mix } \\
\text { at } 1.5 x\end{array}$ & 50 & 14 & 5.1 & 0.7 & 6.1 & 1.8 & 0.7 \\
\hline \multicolumn{8}{|l|}{ Osmocote at $0.5 x$} \\
\hline plus Peters & 55 & 12 & 5.5 & 1.0 & 7.0 & 1.8 & 0.7 \\
\hline Osmocote at $1 \times$ & 50 & 13 & 4.9 & 0.6 & 5.6 & 2.0 & 0.6 \\
\hline Sufficient ${ }^{2}$ & & 3.8 & -4.4 & $0.3-0.5$ & $2.6-3.5$ & $1.4-2.00$ & $.2-0.4$ \\
\hline $\mathrm{LSD}_{0.05}$ & 3.2 & 1.5 & 0.4 & 0.15 & 0.27 & 0.23 & 0.09 \\
\hline
\end{tabular}

${ }^{\bar{z}}$ Dole and Wilkins, 1989.

water-soluble fertilizer or water-soluble fertilizer plus resin-coated fertilizer. Micronutrients were for all treatments were all within a sufficient range.

Poinsettia. The poinsettia trial began 7 Aug. 1989, when 2.5- to 3inch (6. to $7.5-\mathrm{cm}$ ) A.H. Diva Starlight cuttings were stuck in net pots filled with Metro-Mix 350 and placed under intermittent mist with 70F (21C) minimum night temperature. Rooted cuttings were removed from the mist 3 weeks later, planted one per 6.5-inch $(16.5 \mathrm{~cm})$ pot in amended Metro-Mix 350 , and placed on staggered 15-inch $(38-\mathrm{cm})$ centers in awhitewashed glass greenhouse with a 67F (19.5C) minimum night temperature. Plants were pinched to seven leaves when roots had reached the sides and bottom of the pots (11 Sept). Plants were sprayed with Cycocel (chlormequat) at $1500 \mathrm{ppm}$ a.i. (1.5 g a.i./liter) on 25 Sept., when shoots were 1.5 to 2 inches $(3.8$ to $5 \mathrm{~cm}$ ) long, and again 9 and 23 Oct. Foliar samples (24 most

Table 3. Poinsettia A.H. Diva Starlight growth and foliar elemental concentrations with different fertilizer regimes.

\begin{tabular}{|c|c|c|c|c|c|c|c|}
\hline \multirow[b]{2}{*}{ Treatment } & \multicolumn{2}{|c|}{ Plant growth $(\mathrm{cm})$} & \multicolumn{5}{|c|}{ Element (\%) } \\
\hline & Height & Diameter & $\mathbf{N}$ & $\mathbf{P}$ & $\mathrm{K}$ & $\mathrm{Ca}$ & $\mathrm{Mg}$ \\
\hline Control & 18 & 28 & 4.2 & 0.4 & 2.4 & 1.7 & 0.7 \\
\hline Peters alone $(200 \mathrm{ppm} \mathrm{N})$ & 25 & 47 & 6.1 & 1.0 & 2.9 & 1.6 & 0.8 \\
\hline $\begin{array}{l}\text { Poinsettia mix at } 0.5 \times \\
\text { plus Peters }\end{array}$ & 24 & 43 & 6.2 & 0.9 & 2.9 & 1.3 & 0.8 \\
\hline Poinsettia mix at $1 x$ & 24 & 44 & 5.7 & 0.7 & 3.0 & 1.4 & 1.0 \\
\hline Poinsettia mix at $1.5 \times$ & 24 & 40 & 5.9 & 0.9 & 2.7 & 1.4 & 1.0 \\
\hline $\begin{array}{l}\text { Osmocote at } 0.5 \times \\
\text { plus Peters }\end{array}$ & 22 & 43 & 5.8 & 0.8 & 2.7 & 1.5 & 0.9 \\
\hline Osmocote at $l x$ & 23 & 43 & 5.3 & 0.5 & 2.6 & 1.5 & 0.8 \\
\hline Sufficient $^{z}$ & & & $3.8-4.4$ & $0.3-0.5$ & $2.6-3.5$ & $1.4-2.00$ & $2-0.4$ \\
\hline $\mathrm{LSD}_{0.05}$ & 1.7 & 3.8 & 0.52 & 0.08 & 0.23 & 0.20 & 0.09 \\
\hline
\end{tabular}

${ }^{z}$ Dole and Wilkins, 1989.

recently expanded leaves among three subsamples within each replication) for nutrient analyses and plant growth data were collected on $11 \mathrm{Dec}$. Days to flower were determined from the day plants were removed from the mist house and planted until pollen was observed.

Plants produced with water-soluble fertilizer alone were generally taller and wider compared to plants produced with Osmocote at $0.5 \times$ rate plus Peters or Osmocote at $1 \times$ rate (Table 3 ). All other treatments were similar with respect to height and width. There were no significant differences in flower size, days to flower, or flower number among the treatment groups. Leaf elemental concentrations among treatments in this trial were generally similar to those in the zonal geranium and potted chrysanthemum trials. Nitrogen concentrations and, to a lesser extent, $P$ levels, were higher for all treatments than those ofchrysanthemum or zonal geranium.
Zonal geraniums, potted chrysanthemums, and poinsettias produced with the recommended rates of Sierra Geranium Mix 13-12-11 Plus Minors, Sierra Chrysanthemum Mix 12 10-17 Plus Minors, or Sierra Poinsettia Mix 12-12-15 Plus Minors were of comparable quality at harvest as those fertilized with Osmocote 19-6-12, Peters 20-10-20 Peat-Lite Special at every irrigation, or a combination of $0.5 \times$ resin-coated plus water-soluble fertilizer. For zonal geraniums, plants produced with standard Osmocote were significantly smaller than plants produced with the geranium-specific mix and the other fertilizer treatments. Leaf elemental concentrations of resin-coated fertilizer produced plants were generally below those of plants that received water-soluble fertilizer, but they were typically within the range to support optimum crop growth (Dole and Wilkins, 1989). The exception was Ca concentration, which was insufficient for all treatments for zonal geraniums excluding Osmocote at the 1x rate. Foliar nutritional levels, especially $\mathrm{N}$, from water-soluble or combination treatments were excessive or at the upper range of desirability. High elemental concentrations, in the range observed in this study, have been associated with reduced postproduction quality in fresh-cut (Joiner and Smith, 1962) and potted chrysanthemum (Prince et al., 1990).

The crop specific mixes provided adequate nutrients for satisfactory quality crop production and proved to be a satisfactory alternative type of fertilizer compared to Osmocote 196-12 or Peters water-soluble Peat-Lite Special at 200 ppm N concentration.

\section{Literature Cited}

Dole, J.M. and H.F. Wilkins. 1989. Tissue analysis standards. Grower Talks. 21 Aug.

Joiner J.N. and T. C. Smith. 1962. Effects of nitrogen and potassium levels on the growth, flowering responses and foliar composition of Chrysanthemum morifolium Bluechip. Proc. Amer. Soc. Hort. Sci. 80:571-580.

Kiplinger, D.C., H.K. Tayama, and G. Staby. 1972. Slow-release fertilizers and fertilizer injection on growth of several lily cultivars. Ohio Florists Assn. Bul. 509:9.

Kovacic, M. T. and E.J. Holcomb. 1981. Effects of controlled-release fertilizers and application methods on growth and leaf 
elemental concentration of Kalanchoe blossfeldiana Pixie. J. Amer. Soc. Hort. Sci. 106(5):549-552.

Maynard, D.N. and O.A. Lorenz. 1979. Controlled-release fertilizers for horticultural crops. Hort. Rev. 1:79-140.

Payne, R.N. and S.M. Adams. 1980. Influence of rate and placement ofslow-release fertilizer on pot plants of African violet grown with capillary mat watering. HortScience 15(5):607-609.

Prince, T.L., H.K. Tayama, T.A. Prince, N.R. Bhat, and S.A. Carver. 1990. Production and postproduction quality of potted chrysanthemum under controlled-re- lease fertilizer regimes. Ohio Florists Assn. Bul. 728:14-7.

Tayama, H.K. and S.A. Carver. 1988. 1987 Poinsettia research report-nutrition and chemical growth regulation. Ohio Florists Assn. Bul. 709:6-8.

\section{Acknowledgement}

We acknowledge the support of Paul Ecke Poinsettias, Encinitas, Calif.; Yoder Brothers, Inc., Barberton, Ohio; Dean s Greenhouse Co., Cleveland, Ohio; Grace/Sierra Co., Fogelsville, Pa.; and Smithers-Oasis,
Kent, Ohio, for donation of poinsettias, chrysanthemums, zonal geranium cuttings, fertilizer/growing medium, and Oasis Strips, respectively. Trade names are used in this publication to provide specific information. Mention of a trade name does not constitute a guarantee of the product or an endorsement by OSU over other products not mentioned. Salaries and research support provided in part by state and federal funds appropriated to the Ohio Agricultural Research and Development Center, The Ohio State Univ., Columbus. Manuscript no. 278-90. 